\title{
Empirical classification of resources in a business model concept
}

\section{Marko Seppänen}

Tampere University of Technology (Finland) marko.seppanen@tut.fi

Received January, 2009

Accepted April, 2009

\section{Abstract:}

The concept of the business model has been designed for aiding exploitation of the business potential of an innovation. This exploitation inevitably involves new activities in the organisational context and generates a need to select and arrange the resources of the firm in these new activities. A business model encompasses those resources that a firm has access to and aids in a firm's effort to create a superior 'innovation capability'. Selecting and arranging resources to utilise innovations requires resource allocation decisions on multiple fronts as well as poses significant challenges for management of innovations. Although current business model conceptualisations elucidate resources, explicit considerations for the composition and the structures of the resource compositions have remained ambiguous. As a result, current business model conceptualisations fail in their core purpose in assisting the decision-making that must consider the resource allocation in exploiting business opportunities. This paper contributes to the existing discussion regarding the representation of resources as components in the business model concept. The categorized list of resources in business models is validated empirically, using two samples of managers in different positions in several industries. The results indicate that most of the theoretically derived resource items have their equivalents in the business language and concepts used by managers. Thus, the categorisation of the resource components enables further development of the business model concept as well as improves daily 


\section{- Intangible Capital}

communication between managers and their subordinates. Future research could be targeted on linking these components of a business model with each other in order to gain a model to assess the performance of different business model configurations. Furthermore, different applications for the developed resource configuration may be envisioned.

Keywords: business model, resource, categorisation, strategy, allocation, resource-based view

\section{Introduction}

The concept of the business model has been designed for aiding exploitation of a business potential of an innovation (Chesbrough \& Rosenbloom, 2002). This exploitation inevitably involves new activities in the organisational context and, therefore, generates a need to select and arrange the resources of the firm in these new activities (Noda \& Collis, 2001). A business model encompasses those resources that a firm has access to (Osterwalder, Pigneur \& Tucci, 2005; Weill \& Vitale, 2001) and aids in managers' efforts to create a superior 'innovation capability' (Francis \& Bessant, 2005). Innovation may come, for example, in the form of new solution in products, processes or administration.

Resource allocation is at the heart of strategic management of a company due to the causal ambiguity of decisions and actions (Barney, 1986). In addition, the resource allocation process is multi-levelled and distributed in the organisation, resulting in decisions that in effect cumulatively direct the long-term direction, characteristics and prosperity of an organization (Bower \& Gilbert, 2007). Furthermore, distributed decision-making on resource allocation in a multi-project environment becomes an act of balancing between multiple targets and includes continuous improvement in resource utilisation (Tidd, Bessant \& Pavitt, 2001). Selecting and arranging resources to utilise innovations in process-based industries requires resource allocation decisions on multiple fronts as well as poses significant challenges for management of innovations (Linton, Walsh \& Morabinto, 2002).

Managing resources and their allocation is equally important for business-as-usual and reacting to environmental changes as well as for innovation to dislocate 


\section{- Intangible Capital}

competitive positions and create new opportunities for novel resource exploitation (Francis \& Bessant, 2005). If a firm can uniquely assemble a bundle of general resources at its disposal, it is able to achieve a sustainable competitive advantage by exploiting a business opportunity (Barney, 2001, 2005; Hall, 1992; Peteraf, 1993). Similarly, even a single resource can create a sustainable competitive advantage given that the resource fulfils VRIO criteria (Barney, 2005). However, resources and combinations of resources produce differing firm performance in high and low technological turbulence (Song, Droge, Hanvanich \& Calantone, $2005)$, thus highlighting the importance of resource allocation decisions.

In this paper, we attempt to contribute to the existing discussion regarding the representation of resources as components in the business model concept. We continue the examination existing in the literature and examine the essence of resources and their composition (Bueno, Morcillo \& Salmador, 2006; Fernández, Montes \& Vázquez, 2000; Seppänen \& Mäkinen, 2007). The developed, structured list of resources in business models is validated empirically, using two different samples ( $\mathrm{n}=10$ and $\mathrm{n}=27$ ) of managers. In addition to mode and agreement rates for each resource category, we use Krippendorff's alpha method to investigate the reliability of raters' agreements. This method should enable us to distinguish differing raters as well as to distinguish differing resource items (Krippendorff, 1980, 2004; Lombard, Snyder-Duch \& Bracken, 2002). Finally, we conclude the paper with a discussion on our findings, suggesting some avenues for further research as well as making an overall assessment of the limitations of this study.

\section{Theoretical background}

\section{Business models}

A business model provides a way for managers to analyse and communicate their strategic choices (Shafer, Smith \& Linder, 2005). However, while a business model facilitates analysis, testing and validation of a firm's strategic choices, it is not in itself a strategy (Yip, 2004). In fact, the business model as a concept provides a link between strategy and operations and enables exploitation of entrepreneurial opportunities (Hedman \& Kalling, 2003). 
The concept of the business model has received much attention in popular management literature. The study of business models is a major topic of strategic management research since the business model concept affects a firm's possibilities for value creation and capture (Amit \& Zott, 2001). Firms are continuously faced with the challenge of exploiting the business potential of innovations. This exploitation inevitably involves new activities in the organisational context and, therefore, creates a need to select and arrange the resources of the firm in these new activities (Noda \& Collis, 2001).

Although current business model conceptualisations elucidate resources, explicit consideration for the composition, the subject matter and the structures of the resource compositions have remained ambiguous (Morris, Schindehutte \& Allen, 2005). Most of the current business models include, for instance, resources such as strategic assets, tangible and intangible assets and physical, human and organisational resources. As a result, current business model conceptualisations fail in their core purpose in assisting the decision-making that considers the resource allocation in exploiting business opportunities.

Convergence of a business model concept and its domain is accentuated by recent research emphasizing integration of strategy and operations (Davenport, Leipold \& Voelpel, 2006). The business model concept has given rise to the emerging approach to firm-level design, in which the resource-based theory (Barney \& Clark, 2007; Barney, 1991; Wernerfelt, 1984) and its successor, theory on dynamic capabilities (Helfat, Finkelstein, et al., 2007), play the central roles. This study focuses on the business model and its components from the RBV perspective, as it has recently been called for (Barney \& Mackey, 2005). As a result, earlier advancements have fallen short in developing comprehensive frameworks and this has resulted in problems identifying and separating resources in their essence from one another.

\section{Resources and their categorisation}

The literature espousing a resource-based view (RBV) has devoted considerable effort to explain how unique resources, as well as bundles of general resources, can create competitive advantage for a firm (Barney, 1991; Barney, Wright \& Ketchen, 2001; Galbreath, 2005; Pitelis, 2004). However, even the RBV has been unable to clarify the set of resources or even definitions of individual resources 


\section{- Intangible Capital}

(Priem \& Butler, 2001). In the real world, there has also been a lack of coherent definitional grounds, since discussions concerning resources tend, in most cases, to be context-specific. Hence, the current literature offers little guidance for companies in tasks involving allocation and communication about resources. Although the company needs to assemble the resources at its disposal to utilize business potential, it must first identify and assess all needed resources in order to understand which resources the firm may have at its disposal and what it still needs to acquire.

There have been fewer works linking specific firm resources and capabilities with the ability to create and implement these kinds of firm strategies (Barney \& Mackey, 2005). This is largely because current typologies of firm resources are very broad in scope, for instance Barney's (2005) distinction between financial, physical, human and organisational resources. The RBV literature has attempted to either list existing resources (Bueno, Morcillo \& Salmador, 2006; Fernández, Montes \& Vázquez, 2000) or build theoretical outcome-related classifications for resources (Amit \& Zott, 2001; Praest, 1998). Although the primary focus of the RBV is on the resources that are able to provide sustainable competitive advantage, so-called complementary resources are also discussed (Barney \& Clark, 2007; Barney \& Mackey, 2005). These complementing resources are nevertheless important if a firm targets to realise the full competitive potential of its resources and strategies.

Categorisation describes the formation and use of natural and social concepts of objects by individuals to organise their worlds (Dutton \& Jackson, 1987). Cognitive theories assume that individuals employ schema to understand their world, that is to say, that schema describes data structures in memory that represent knowledge about concepts. For categorisation, an individual has to differentiate objects from each other. Those attributes serving to differentiate categories are said to have high cue validity. However, such categories are "fuzzy" because of the difficulty of observing prototypical cases in real life (Dutton \& Jackson, 1987). In addition, theoretical models cannot only be constructed between theory and reality but also act as communication devices (Skyttner, 2001).

Therefore, our previous categorization facilitates further development of a hierarchical classification towards individual resources and identification of their 


\section{Intangible Capital}

(c) (c) Intangible Capital, 2009 - 5(2): 102-124 - ISSN: 1697-9818

essence (Seppänen \& Mäkinen, 2007). Due to the theoretically limited representation of resources in the business model concept, we have synthesized the aforementioned propositional categorization of resources based on the current literature (Figure 1). The proposed two-level categorization provides a comprehensive set of resources that a manager should take into consideration when designing the exploitation of innovation.

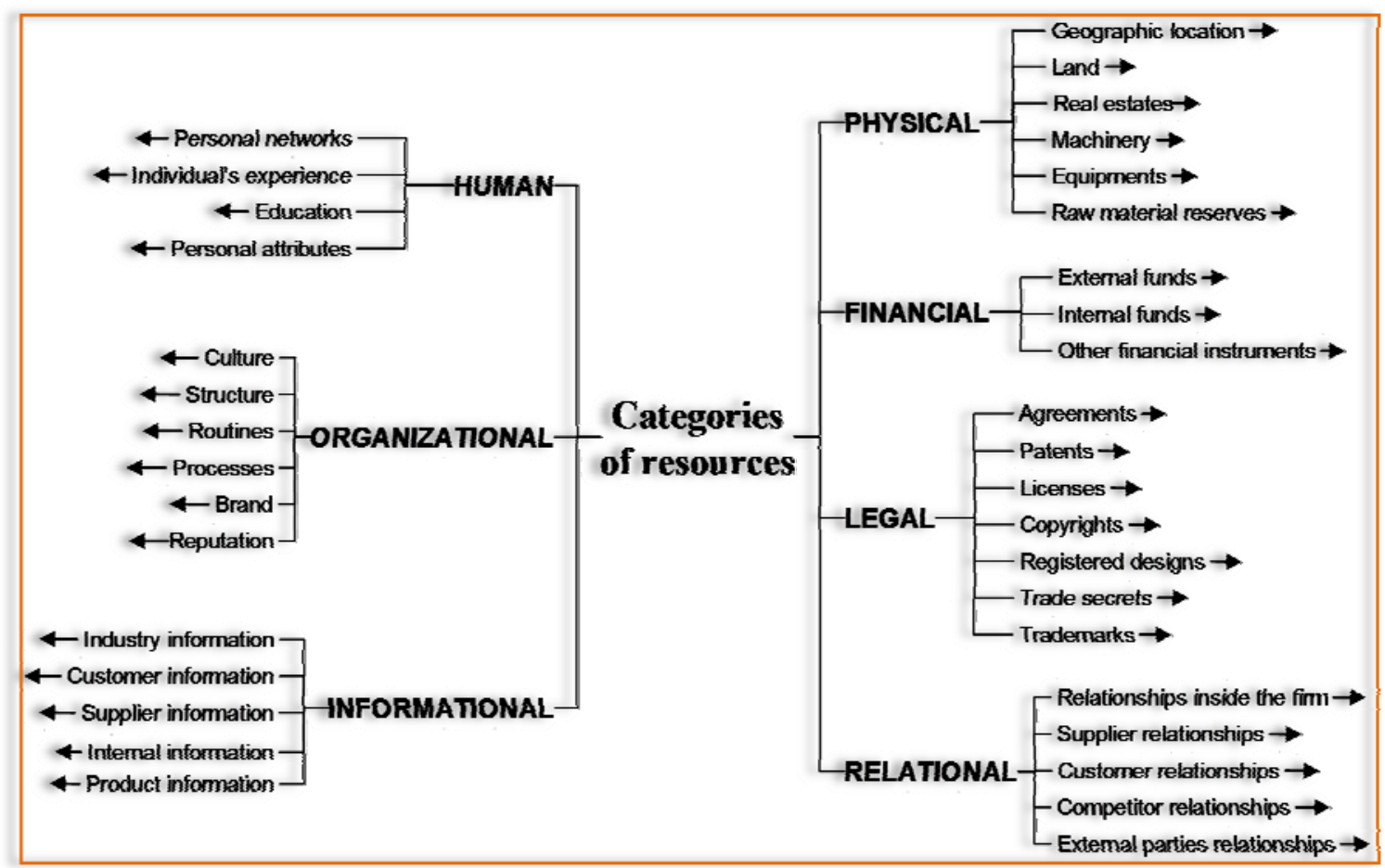

Figure 1. Classification of resources for the business model concept

(Seppänen \& Mäkinen, 2007)

The proposed categorization is built on existing theoretical structures in order to facilitate communication and understanding of the system as a whole and of its categories. The more fine-grained a model is, the more detailed explanations it may offer (Murmann \& Frenken, 2006). Although the categorisation is two-level only, each resource category in Figure 1 includes further sublevels and objects that are denoted with arrowheads; however, these lower-level objects are neither examined nor categorised in the this study (Seppänen \& Mäkinen, 2007). 


\section{Research method and design of the empirical study}

The study examined the decision-making situation in which a business model is designed and managed. We have two different samples due to two main reasons. Firstly, we wanted to examine the comprehensiveness and usefulness of categorisation from the business managers' perspective. For this objective, we decided to accomplish a round of interviews of business managers in order to detect their perceptions on the proposed categorisation as well as to examine their opinions on resource items and their appropriateness on everyday business life. Secondly, we attempted to obtain better validation for the categorisation by using another sample from different industries. Due to the larger sample, we gave up interviewing and utilised the form-based approach. Since the methods for the selected sample groups are different, we will discuss both cases separately. In the following, we describe our research method in more detail.

The first sample group (\#1) consisted of ten business managers who were accustomed to resource discourse and represented multi-project companies from different industries such as telecommunications, software and wholesale. We included different industries in our study, since decisions regarding the business model are carried out similarly in general management positions independent of the industry. The respondents have several years of experience and represent the top-management level (e.g., CEO, Vice President) in their businesses, and educational level for most of them was one of the higher academic degrees. The study setting was designed to provide a single case as a particular decision-making situation in which a business manager has to carry out tasks involving resource allocation, management and communication decisions.

The semi-structured, three-phased interviews were audio-taped and subsequently formed the empirical basis for assessing and evaluating the appropriateness of our categorisation. In the first phase of the interview, each respondent received seven, A5-sized sheets which were labelled as categories of physical, financial, organisational, relational, human, informational and legal. Each respondent was asked to assign each of 36 resource items to these main category sheets. The second phase of the interview involved an actual case, which the respondent was requested to prepare in advance. The respondent was invited to freely describe a practical case example of a product or service from their current offering and the 
resources needed to make a profitable business from it. In the third and final phase of the interview we examined the validity of resource categorisation by using a number of questions that had been prepared beforehand. The first question dealt with the face validity of the categorization and the conventions used to name its resource items. The second question intended to confirm the mutual exclusivity and internal homogeneity of the resources, or, in other words, its internal validity. Similarly, construct validity was examined by asking the following two questions regarding the exhaustiveness and parsimony of the categorization. Finally, the fifth explicit question aimed to ascertain its generalizability, that is, external validity. If the respondent was not able to agree with our question, we asked some follow-up questions to uncover possible underlying reasons more clearly, as well as to obtain possible suggestions for further development of categorization. We complemented our examination by asking several additional questions about the resource listings' comprehensiveness and usefulness from the respondent's perspective.

The final remark on study settings concerns the used language. We decided to use English for our resource terminology in order to avoid translation errors. However, each resource item was translated in the respondent's mother tongue beforehand. The interviews were also held in the respondent's mother tongue to maximize the ability to freely think and describe their thoughts and associations. This procedure can be assessed legitimate since English is the working language for many of the respondents hence they were accustomed to both its use and the terminology of resource discourse in English.

The second sample group (\#2) comprised 27 persons representing mainly the healthcare and relating industries. They were participating in the university's special MBA programme and this part of the study was carried out during their educational period. The respondents have several years of experience in their fields and represent top-management level (e.g., doctors, CEOs) in their organisations, thus we can consider that sample groups represent very similar people. Most of the respondents had higher academic degrees. The study setting involved a listing of same 36 resource items and a template with titles of the seven main resource groups. The resource list was in alphabetic order both in their mother tongue and in English. The respondents were asked to consider each resource item and assign it to the category which they consider to be the most appropriate. As the final data 


\section{- Intangible Capital}

(c) (c) Intangible Capital, 2009 - 5(2): 102-124 - ISSN: 1697-9818

set, we compiled 27 A4-sheets in which all 36 resource items were assigned to the seven main categories.

\section{Results}

All responses are coded and summarised yielding a multinomial distribution: the respondents in both samples have assigned the same 36 resource items into seven main resource categories. Firstly, we present below the mode category for each resource item and the agreement rate between respondents and discuss the findings. Secondly, we use Krippendorff's alpha method to describe the reliability of the raters' agreements in order to distinguish differing raters and to differentiate resource items. This section is concluded with a summary and analysis of the main results with an explanation of our reasoning.

\section{Agreement rate and mode}

Being a typical measure for the nominal scale, agreement rate explains the percentage of the respondents who assigned the resource item into the mode category. Furthermore, mode for a variable characterizes well the nominal scale (Sirkin, 2005). As Table 1 illustrates, for most of the resources the respondents had fairly good agreement on the main category since for most of the resources the agreement rate was over $60 \%$. However, the second sample group's agreement rates were lower than the first group's.

In the first sample group only four resources produced divided opinions: reputation (\#17), brand (\#21) and relationships inside the firm (\#14) and trade secrets (\#36) all had the agreement rate less than $60 \%$. Considering the results of the first group, the same resources-excluding trade secrets-were assigned differently when compared to our initial proposal for resource categorisation (Seppänen \& Mäkinen, 2007). This distribution clearly indicates that these resources do have varying connotations in the respondents' minds.

In the second sample group, the same three resources, namely brand, reputation and relationships inside the firm have a large distribution of opinions, the agreement rate being clearly below $60 \%$. In addition, culture had a quite low agreement rate, only $44 \%$ and it was assigned to the Organizational resource category. The trade secrets item, which was dividing opinions in the first group, 
now has an agreement rate well over $60 \%$ and is assigned to the legal resource category.

\begin{tabular}{|c|c|c|c|c|c|}
\hline \multirow[b]{2}{*}{ \# } & \multirow[b]{2}{*}{ Resource item } & \multicolumn{2}{|c|}{ SAMPLE \#1 $(\mathrm{n}=10)$} & \multicolumn{2}{|c|}{ SAMPLE \#2 $(n=27)$} \\
\hline & & Mode & Agreement rate & Mode & Agreement rate \\
\hline 1 & Equipments & Physical & $100 \%$ & Physical & $89 \%$ \\
\hline 2 & Land & Physical & $90 \%$ & Physical & $56 \%$ \\
\hline 3 & Real estates & Physical & $90 \%$ & Physical & $56 \%$ \\
\hline 4 & Machinery & Physical & $80 \%$ & Physical & $67 \%$ \\
\hline 5 & Raw material reserves & Physical & $80 \%$ & Physical & $59 \%$ \\
\hline 6 & Geographic location & Physical & $70 \%$ & Physical & $70 \%$ \\
\hline 7 & External funds & Financial & $100 \%$ & Financial & $100 \%$ \\
\hline 8 & Internal funds & Financial & $100 \%$ & Financial & $96 \%$ \\
\hline 9 & Other financial instruments & Financial & $100 \%$ & Financial & $96 \%$ \\
\hline 10 & Processes & Organizational & $80 \%$ & Organizational & $89 \%$ \\
\hline 11 & Routines & Organizational & $70 \%$ & Organizational & $67 \%$ \\
\hline 12 & Structure & Organizational & $70 \%$ & Organizational & $100 \%$ \\
\hline 13 & Culture & Organizational & $50 \%$ & Organizational & $44 \%$ \\
\hline 14 & Relationships inside the firm & Organizational & $40 \%$ & Relational & $48 \%$ \\
\hline 15 & Competitor relationships & Relational & $80 \%$ & Relational & $70 \%$ \\
\hline 16 & Other external parties relationships & Relational & $80 \%$ & Relational & $85 \%$ \\
\hline 17 & Brand & Relational & $50 \%$ & Legal & $48 \%$ \\
\hline 18 & Customer relationships & Relational & $70 \%$ & Relational & $85 \%$ \\
\hline 19 & Supplier relationships & Relational & $70 \%$ & Relational & $63 \%$ \\
\hline 20 & Personal networks & Human & $70 \%$ & Relational & $74 \%$ \\
\hline 21 & Reputation & Human & $30 \%$ & Relational & $41 \%$ \\
\hline 22 & Education & Human & $90 \%$ & Human & $67 \%$ \\
\hline 23 & Experience & Human & $90 \%$ & Human & $78 \%$ \\
\hline 24 & Personal attributes & Human & $90 \%$ & Human & $85 \%$ \\
\hline 25 & Industry information & Informational & $90 \%$ & Informational & $59 \%$ \\
\hline 26 & Internal process information & Informational & $80 \%$ & Informational & $59 \%$ \\
\hline 27 & Customer information & Informational & $80 \%$ & Informational & $74 \%$ \\
\hline 28 & Product information & Informational & $80 \%$ & Informational & $81 \%$ \\
\hline 29 & Supplier information & Informational & $80 \%$ & Informational & $59 \%$ \\
\hline 30 & Copyrights & Legal & $100 \%$ & Legal & $96 \%$ \\
\hline 31 & Registered designs & Legal & $100 \%$ & Legal & $93 \%$ \\
\hline 32 & Trademarks & Legal & $100 \%$ & Legal & $81 \%$ \\
\hline 33 & Licenses & Legal & $90 \%$ & Legal & $81 \%$ \\
\hline 34 & Patents & Legal & $90 \%$ & Legal & $89 \%$ \\
\hline 35 & Agreements & Legal & $60 \%$ & Legal & $85 \%$ \\
\hline 36 & Trade secrets & Legal & $40 \%$ & Legal & $67 \%$ \\
\hline
\end{tabular}

Table 1. The mode category and the agreement rate for each resource item

More interestingly, the respondents of the second sample group had a dichotomised distribution between physical and financial resource categories for the following resources: land (\#2), real estate (\#3) and raw material reserves (\#5). This difference between our samples-despite the fact that respondents in both samples represent fairly homogenous individuals in terms of education and current positions-was also statistically very significant $(p=0.000)$ according to the MannWhitney $U$ test. The agreement rates were just below $60 \%$. Similarly, agreement 


\section{Intangible Capital}

rates were $59 \%$ for three types of informational resources: industry (\#25), internal process (\#26) and supplier (\#29) information.

Figure 2 below represents the distribution for these resource items and shows concurrently that the respondents have assigned these resources to four to five different main categories. Although the 16 respondents had agreed on the informational resource category, the result indicates that respondents obviously do have differing perceptions on these resource items.

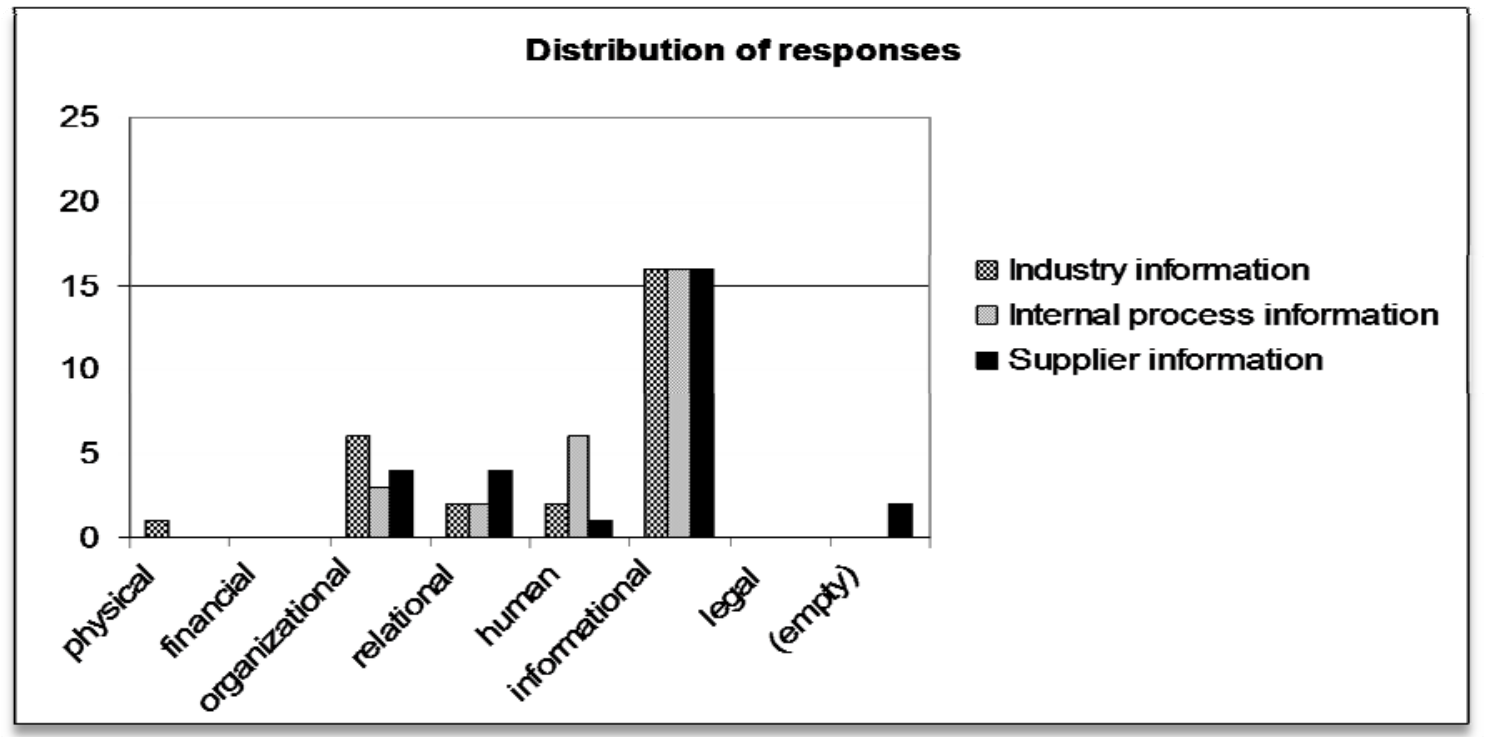

Figure 2. Distribution of responses for three types of informational resources in sample group \#2.

\section{Reliability assessment between the raters}

We use Krippendorff's alpha (hereafter, K-alpha) method to describe the reliability of raters' agreements in order to distinguish differing raters as well as to distinguish differing resource items (Krippendorff, 1980, 2004; Lombard, SnyderDuch \& Bracken, 2002). Table 2 interprets the significance of the alpha value as was suggested by Landis \& Koch (Landis \& Koch, 1977). The alpha is usually higher when there are fewer categories ( $\operatorname{Sim} \&$ Wright, 2005) whereas smaller samples could result in larger differences and lower alpha (Lombard, Snyder-Duch \& Bracken, 2004). Moreover, lower criteria can be used for indices known to be more conservative (Lombard, Snyder-Duch \& Bracken, 2002). 


\begin{tabular}{rr}
\hline K & Interpretation \\
\hline$<0$ & Poor agreement \\
$0.0-0.20$ & Fair agreement \\
$0.21-0.40$ & Slight agreement \\
$0.41-0.60$ & Moderate agreement \\
$0.61-0.80$ & Substantial agreement \\
$0.81-1.00$ & Almost perfect agreement \\
\hline
\end{tabular}

Table 2. Interpretation of the Krippendorff's alpha value

K-alpha reliability estimates were calculated using SPSS software and a macro provided by Hayes \& Krippendorff (Hayes \& Krippendorff, 2007). For all respondents (Run $\# 1$ ), the $K$-alpha has the value of 0.60 , indicating that it was just at the border between moderate and substantial agreement (see Table 3). Excluding the four resource items with a large spread (Run \#2) raises the value of $\mathrm{K}$-alpha to 0.66. Furthermore, we were interested in determining whether the respondents differ from one another. We calculated the $\mathrm{K}$-alpha by excluding each respondent one by one from our data (Run \#3), revealing three respondents whose categorizations differed remarkably from the other seven. When these three respondents were excluded (leaving seven respondents), the $K$ alpha value rose to 0.76. Furthermore, when the four large-spread resource items (Run \#4) were again excluded, we obtained a $\mathrm{K}$-alpha value of 0.83 . According to Table 2 , this result indicates almost perfect agreement between the seven respondents for those 32 resource items.

\begin{tabular}{rrrrrrr}
\hline Run & Alpha & LL95\%CI & UL95\%CI & Units & Observers & Pairs \\
\hline$\# 1$ & 0.60 & 0.57 & 0.63 & 36 & 10 & 1620 \\
$\# 2$ & 0.66 & 0.63 & 0.69 & 32 & 10 & 1444 \\
$\# 3$ & 0.76 & 0.72 & 0.79 & 36 & 7 & 756 \\
$\# 4$ & 0.83 & 0.80 & 0.86 & 32 & 7 & 672 \\
$\# 5$ & 0.54 & 0.53 & 0.55 & 36 & 27 & 12636 \\
$\# 6$ & 0.58 & 0.56 & 0.59 & 32 & 27 & 11232 \\
\hline
\end{tabular}

Table 3. K-alpha reliability estimates for the first sample (\#1)

Regarding the second sample (\#2), we calculated the overall K-alpha reliability estimates. These are presented as Runs \#5 and \#6 having the value of 0.54 and 0.58 , respectively. For Run \#5 the result indicates moderate agreement among all 


\section{- Intangible Capital}

of the raters for all resource items. For Run \#6 we excluded once again the same four questionable resource items in order to see comparable figures with the first sample. The result indicates again moderate agreement between the raters. A similar rotational test for discovering differing respondents in this sample was not carried out. However, there seems to be some response profiles that clearly differ from most of the response profiles thus this rotational testing should be carried out in further studies.

\section{Discussion and managerial implications}

Our results indicate that most of the theoretically derived resource components have their equivalents in the business language and concepts used by managers. The more detailed analysis presented above shows that our respondents in both sample groups perceived and therefore assigned only the following resource items differently: brand (\#17) and reputation (\#21). In addition, the first group assigned differently two resource items, namely trade secrets (\#36) and relationships inside the firm (\#14), compared to our theoretical categorisation. Common to all these resource items is quite naturally their wide distribution in responses: each of them was assigned three to four separate main categories thus indicating wide variation in the perceptions of our respondents. Furthermore, we detected an interesting dichotomised distribution in three resource items, namely land, raw material reserves and real estate were all assigned either to the physical or to the financial main category. One explanation may be the well-functioning aftermarkets for each of those; even though their appearance inevitably is physical, managers seem to consider them mainly as financial resources.

Our results indicated that the proposed resource categorisation was, in principle, appropriate for its intended use as a part of the business model concept. More specifically, no fewer than 32 of 36 resource items had the substantial agreement between respondents measured by Krippendorff's alpha in our first sample group. In addition, we analysed in more detail the four resource items whose assignments had the largest spread in the respondents' answers. Here we found that the items reflected a variety of perceptions depending on the respondent's individual emphasis and managerial style. 


\section{- Intangible Capital}

However, the results of the second sample group revealed that managers from different industrial backgrounds seem to have quite different perceptions, as was revealed by the statistical test for the two independent groups. Partly this is due to different sample sizes but seemingly, there is significant difference in respondents' opinions. To examine more closely the possible reasoning behind the respondents' assignments, we returned to our interview recordings of the first group that included the respondents' spoken thoughts while they processed the content of each resource label.

We separated these explanations into each main category since all explanations in one way or another are based on the content of the main category's label. Several times, we briefly discussed whether these labels describe well their content or whether we should label them somehow differently. In these discussions, the language issue emerged since all the respondents appeared to think in their mother tongue and were therefore obliged to translate the label (and its meaning) into their mother tongue. Although the respondents used English as their working language on the job and had relatively high educational backgrounds, this issue nevertheless caused some hesitancy in making decisions. Discussions that are more detailed revealed that all the respondents were able to agree on the selected label and accept it as describing the meaning of a particular resource item. The selected quotes attempt to illustrate how the respondents rationalized their assignments.

Some of the respondents stated that reputation and brand exist primarily in relation to others; therefore, they considered those as relational resources, since "No business is an island." In addition, relationships inside the firm are explicitly relational resources, not organizational resources, which was another option:

Relationships inside the firm are important... This resource categoryRelational-is about the firm's relations with the outside world... this resource item is not about relations with others, but it emphasizes the inner relations of the firm.

Overall, the most difficult resource item for all the respondents seemed to be brand, as it caused all respondents to stop briefly, think twice as to its real meaning and where to assign it. However, when asked, they admitted that it is an 


\section{- Intangible Capital}

item similar in type and size to the others, though a somewhat more complex item to deal with. The following quote exemplifies this issue:

Brand is a somewhat emotional issue ... to take care of a given proposal by the firm's brand... Human, perhaps, they will communicate the brand to other parties, after all... no firm can support a brand that is not believed and shared by its personnel, they have to understand the market...

For one respondent, the brand was primarily perceived as a legal item: "You have legal rights to your brand" and the brand was therefore compared to the trademark as a company's resource. For the assignment of brand, one respondent offered the following reasoning:

A brand is created in an interaction between different interest groups... it's not endogenous, but quite the contrary... The value of a brand is based on how the others prize you, not how you prize yourself...

The trade secrets item was assigned to the financial resource category, since its monetary value was emphasized instead of its other meanings. Several respondents recognized that many of these resource items indeed have monetary value or their monetary value can be calculated. The second group also detected this issue in the physical resource category. However, as the following quote emphasizes, confidentiality issues referring to resource category and ownership perspective were present in assignment decision:

Individuals own trade secrets, information that should not be revealed although some people have a pathological willingness to expose others' confidential secret.

The informational character of reputation and brand was underlined when these resources were assigned to the informational resource category. Reputation and brand are primarily information about previous matters done by the organization. Similarly, trade secrets are, as such, information:

Trade secrets are most often information about somebody or something; hence I assigned this to the informational resource category. 


\section{- Intangible Capital}

Based on our investigations, we suggest that resource categorisation may have many practical uses. First, the categorisation clarifies practicing managers' cognitive mapping of objects by providing a comprehensive inventory of resources for the exploitation of business potential. Furthermore, the categorisation could serve as a potential checklist to identify what to develop further in a firm.

Second, the categorisation improves communication between actors concerning the sets of resources. The governance role that each manager has adopted is reflected, to some degree, in their responses and emphasis of resources. For instance, the manager who was used to ensuring a free flow of information and, in general, its role in decision-making, stressed informational perspectives also in this interview. Additionally, the manager whose role involves predominantly financial issues displayed a clearer financial perspective than the other respondents did. This was revealed in several comments, which speculated on the monetary value of each resource. Nevertheless, both types of manager considered resource categorisation useful for the purposes of a business model concept.

Finally, categorisation in exploiting business potential facilitates a fuller understanding of the resources that need to be assembled. The use of categorisation for exploiting business potential provides a linkage between operations and strategy; that is, between activities and long-term planning. The resource perspective, therefore, enables concurrent two-level examinations of a firm's resources: a view of the overall resources and the view of each individual resource. In implementation of a firm's strategy, communication about resource allocation decisions plays the key role. This is recently emphasised, for instance, by Bower \& Gilbert (2007): "The leadership challenge is to give coherent direction to how resources are allocated and, by doing so, align the bottom-up processes with top-down objectives." This cannot be done-or they are likely to encounter problems in communication-if the managers cannot speak the same language with their subordinates.

\section{Limitations of the study}

There are certain aspects of this study that merit further comment. The first limitation is in regards to the study setting. Although we were interested in managers' perceptions for resources and their categorisation, the fact was that we had prepared in advance a theoretical framework which was actually tested in this 


\section{- Intangible Capital}

study setting. Therefore, we had already made important decisions concerning the linguistics representation of resources and this affects the results. Due to continuous struggle between exactness and usefulness of the concept in strategic management theory and practice, we cannot define such concepts as, e.g., is suggest by the taxonomic tradition in biology. However, the concepts used in theoretical considerations should be derived from commonly used business concepts having established meanings. Another option would have been to use an explorative interviewing technique in order to recognize used resource concepts from the managerial discourse. However, our basic assumption has been that the extant literature should include all resource concepts being widely used thus justifying our assumption concerning construct validity.

Another limitation concerns the method used in the study. We designed the study to acquire data about managers' perceptions on resources in a particular decisionmaking situation involving such tasks as resource allocation, management and communication decisions. Because the research instrument was artificial and the managers' decisions were not examined in their real-life situations, this setting may have caused several sources of error and bias, e.g., respondent biases, and biases or errors in the interviews. We used a reliability analysis to examine the effects of these possible biases. Furthermore, the study is conducted in Finland and the nationality of all the respondents was Finnish. Evidently, this might be a source of country-specific bias.

The selection of respondents even though carefully designed was to a certain extent based on access. This limitation took place in selecting the second sample where it was decided to use participants of the MBA programme. However, we did not select the participants of this programme. In addition, a small number of respondents in the first sample may have caused some unreliability. We attempted to assess and minimize this potential deficiency using the inter-rater agreement method. Nevertheless, it would be helpful if further studies could use larger samples including respondents from other industry sectors.

Finally, our study setting further assumes that managerial level is one of the most important levels in business management. Considering the amount of communication within an organisation, we should not forget other levels such as middle management and employees. Although intentional decisions regarding 


\section{- Intangible Capital}

business models-that was our pervasive perspective-are made primarily at the managerial level, communication about resource allocation decisions has to relate to all personnel. Further studies could examine the resource discourse from the other perspectives.

\section{Conclusion}

This study examined managers' perceptions on a theoretically derived resource categorisation and its items that were developed for the purposes of the business model concept. This objective was accomplished by using different samples: firstly, interviewing ten business managers representing multi-project companies from different industries, and secondly, surveying perceptions of 27 managers mainly in healthcare and related industries to complement our investigations.

Our results demonstrate that theoretically derived resource components have their equivalents in the business language and concepts used by managers in our samples. More specifically, in the first sample, the respondents achieved substantial inter-rater agreement whereas in the second sample the respondents achieved moderate inter-rater agreement on the proposed resource categorisation. Thus, we may state that the examined resource categorisation and its components enable developing the business model concept further as well as the categorisation improves daily communication between managers and their subordinates. Several resources need to be examined in more detail or otherwise need to be defined differently since their perceptions varied remarkably. We analyzed in more detail those four resource items whose assignments had the largest spread in the respondents' answers and found that they typically had several competing perceptions depending on the respondent's emphasis and managerial style. However, in our study setting we were not able to examine this phenomenon at length.

Further research can be targeted at developing improved segregation for these resource items. The identified conflicts between some of the examined resource items could be solved, for instance, by redefining those resources. Moreover, future research could be targeted on linking the components of the business model with each other in order to gain a model to assess the performance of different business model configurations. Different applications for the resource configuration 


\section{- Intangible Capital}

(c) (c) Intangible Capital, 2009 - 5(2): 102-124 - ISSN: 1697-9818 doi: 10.3926/ic.2009.v5n2.p102-124

may be envisioned. For example, the resource categorisation can be used as a part of disruptive technology road mapping, which includes renewing resource exploitation with multiple stakeholders and differing resource configurations.

\section{References}

AMIT, R., \& ZOTT, C. (2001). Value Creation in E-Business. Strategic Management Journal, 22: 493-520.

BARNEY, J. (1986). Organizational Culture: Can it be a source of competitive advantage? Academy of Management Review, 11(3): 656-665.

BARNEY, J . (1991). Firm resources and sustained competitive advantage. Journal of Management, 17(1): 99-120.

BARNEY, J. (2001). Resource-based theories of competitive advantage: A ten-year retrospective on the resource-based view. Journal of Management, 27: 643-650.

BARNEY, J. (2005). Gaining and sustaining competitive advantage. New Jersey: Prentice Hall - Pearson.

BARNEY, J. \& CLARK, D. N. (2007). Resource-Based Theory. Creating and Sustaining Competitive Advantage: Oxford University Press.

BARNEY, J., \& MACKEY, T. B. (2005). Testing Resource-Based Theory. In D. J. Ketchen \& D. D. Bergh (Eds.), Research methodology in strategy and management (pp. 1-13). New York: Elsevier.

BARNEY, J., WRIGHT, M. \& KETCHEN, D. J. J. (2001). The resource-based view of the firm: Ten years after 1991. Journal of Management, 27: 625-641.

BOWER, J. L., \& GILBERT, C. G. (2007). How Managers' Everyday Decisions Create or Destroy Your Company's Strategy. Harvard Business Review, 85(2): 72-79.

BUENO, E., MORCILLO, P. \& SALMADOR, M. P. (2006). Distinctions that matter: A classification of resources and discussion of implications for dynamic capabilities of firms. International J ournal of Management Practice, 2(1): 72-82. 


\section{- Intangible Capital}

CHESBROUGH, H. \& ROSENBLOOM, R. S. (2002). The role of the business model in capturing value from innovation: Evidence from Xerox Corporation's technology spin-off companies. Industrial and Corporate Change, 11(3): 529-555.

DAVENPORT, T. H., LEIPOLD, M., \& VOELPEL, S. (2006). Strategic Management in the Innovation Economy. Germany: Publics Corporate Publishing \& Wiley GmbH.

DUTTON, J. E. \& JACKSON, S. E. (1987). Categorizing Strategic Issues: Links to Organizational Action. Academy of Management Review, 12(1): 76-90.

FERNÁNDEZ, E., MONTES, J. M. \& VÁZQUEZ, C. J. (2000). Typology and strategic analysis of intangible resources: A resource-based approach. Technovation, 20: 81-92.

FRANCIS, D. \& BESSANT, J. (2005). Targeting innovation and implications for capability development. Technovation, 25: 171-183.

GALBREATH, J. (2005). Which resources matter the most to firm success? An exploratory study of resource-based theory. Technovation, 25: 979-987.

HALL, R. (1992). The Strategic Analysis of Intangible Resources. Strategic Management Journal, 13(2): 135-144.

HAYES, A. F. \& KRIPPENDORFF, K. (2007). Answering the call for a standard reliability measure for coding data. Communication Methods and Measures, 1(1): 77-89.

HEDMAN, J. \& KALLING, T. (2003). The business model concept: Theoretical underpinnings and empirical illustrations. European Journal of Informations Systems, 12: 49-59.

helfat, C. E., fINKELSteIN, S., MITCHELL, W., PeterAF, M. A., SINGH, H., TEECE, D. J., et al. (2007). Dynamic capabilities. Understanding strategic change in organizations: Blackwell publishing.

KRIPPENDORFF, K. (1980). Content Analysis: An Introduction to its Methodology (2nd ed.). Beverly Hills: Sage. 


\section{- Intangible Capital}

(c) (c) Intangible Capital, 2009 - 5(2): 102-124 - ISSN: 1697-9818 doi: 10.3926/ic.2009.v5n2.p102-124

KRIPPENDORFF, K. (2004). Reliability in Content Analysis - Some Common Misconceptions and Recommendations. Human Communication Research, 30(3): 411-433.

LANDIS, J. R. \& KOCH, G. G. (1977). The measurement of observer agreement for categorical data. Biometrics, 33: 159-174.

LINTON, J. D., WALSH, S. T. \& MORABINTO, J. (2002). Analysis, ranking and selection of $R \& D$ projects in a portfolio. $R \& D$ Management, 32(2): 139-148.

LOMBARD, M., SNYDER-DUCH, J. \& BRACKEN, C. (2002). Content analysis in Mass Communication: Assessment and Reporting of Intercoder Reliability. Human Communication Research, 28(4): 587-604.

LOMBARD, M., SNYDER-DUCH, J. \& BRACKEN, C. C. (2004). A Call for Standardization in Content Analysis Reliability. Human Communication Research, 30(3): 434-437.

MORRIS, M., SCHINDEHUTTE, M., \& ALLEN, J. (2005). The entrepreneur's business model: Toward a unified perspective. Journal of Business Research, 58: 726-735.

MURMANN, J.P. AND FRENKEN, K. (2006), Toward a systematic framework for research on dominant designs, technological innovations, and industrial change. Research Policy. 35: 925-952.

NODA, T. \& COLLIS, D. (2001). The evolution of intra-industry firm heterogeneity: Insights from a process study. Academy of Management Journal, 44: 897-925.

OSTERWALDER, A., PIGNEUR, Y. \& TUCCI, C. L. (2005). Clarifying business models: Origins, present, and future of the concept. Communications of the Association for Information Systems, 16(1).

PETERAF, M. A. (1993). The Cornerstones of Competitive Advantage: A ResourceBased View. Strategic Management Journal, 14: 179-191.

PITELIS, C. N. (2004). Edith Penrose and the resource-based view of (international) business strategy. International Business Review, 13: 523-532. 


\section{- Intangible Capital}

PRAEST, M. (1998). Changing technological capabilities in high-tech firms: A study of the telecommunications industry. The Journal of High Technology Management Research, 9(2): 175-193.

PRIEM, R. L. \& BUTLER, J. E. (2001). Is the resource-based "view" a useful perspective for strategic management research? Academy of Management Review, 26(1): 22-40.

SEPPÄNEN, M. \& MÄKINEN, S. (2007). Towards a classification of resources for the business model concept. International Journal of Management Concepts and Philosophy, 2(4): 389-404.

SHAFER, S. M., SMITH, H. J. \& LINDER, J. (2005). The power of business models. Business Horizons, 48: 199-207.

SIM, J. \& WRIGHT, C. C. (2005). The Kappa Statistic in Reliability Studies: Use, Interpretation, and Sample Size Requirements. Physical Therapy, 85: 257-268.

SIRKIN, R. M. (2005). Statistics for the Social Sciences. Cambridge: SAGE Publications Ltd.

SKYTTNER, L. (2001). General systems theory. Ideas \& applications: World Scientific Press.

SONG, M., DROGE, C., HANVANICH, S. \& CALANTONE, R. (2005). Marketing and technology resource complementarity: an analysis of their interaction effect in two environmental contexts. Strategic Management Journal, 26(3):259-276.

TIDD, J., BESSANT, J. \& PAVITT, K. (2001). Managing Innovation. Integrating Technological, Market and Organizational Change (2nd ed.): John Wiley \& Sons Ltd.

YIP, G. S. (2004). Using Strategy to Change Your Business Model. Business Strategy Review, 15(2): 17-24.

WEI LL, P. \& VITALE, M. R. (2001). Place to Space. Migrating to eBusiness Models. Boston: Harvard Business School Press. 
WERNERFELT, B. (1984). A Resource-Based View of the Firm. Strategic Management Journal, 5(2): 171-180.

El artículo está con Reconocimiento-NoComercial 2.5 de Creative Commons. Puede copiarlo, distribuirlo y comunicarlo públicamente siempre que cite a su autor y a Intangible Capital. No lo utilice para fines comerciales. La licencia completa se puede consultar en http://creativecommons.org/licenses/by-nc/2.5/es/ 